It is of concern that among the 12 who rated their knowledge as poor or nil, six had had more than two years in psychiatric training. Fortunately, St George's Training Scheme has a Mental Health Act Day in the regional Part II course. The Day is also open to GPs. Participants are taken through the MHA and discuss applying the MHA in case vignettes.

Psychiatrists will have to lead the way in knowledge and application of the MHA. Indeed, one respondent to the survey wrote that GPs often called the duty doctor to ask how to 'section' patients!

Jeyabala BalaKRISHNA, Atkinson Morley's Hospital Wimbledon, London SW2O

Sir: I was concerned to read Dr Balakrishna's letter and note the poor level of knowledge about the Mental Health Act described.

No doubt all those concerned in the training of junior psychiatrists will note this. I was also disappointed, but not surprised, to be reminded that trainees perceive the presence of a topic in an examination to be a particular spur to the acquisition of knowledge. There are many very important areas in psychiatry which cannot be examined formally in the MRCPsych examinations, knowledge of which is vital for practising psychiatrists. At the present time it has not proved practicable in written examinations to examine fairly the minutiae of four different Mental Health Acts, although the principles behind Mental Health legislation, as trainees will be aware, are examined. Any aspect of mental health legislation is likely to be a topic in clinical and oral examinations provided examiner and examined are acquainted with the same jurisdiction.

Section 12 approval, in England and Wales, is of course granted by regional health authorities and I know that discussions are taking place as to how best to ensure that those given section 12 approval have an adequate knowledge of the Mental Health Act. I am sure that Dr Balakrishna's letter will remind all psychiatrists of the importance of ensuring that they personally acquire adequate knowledge of this subject.

Sheila ManN, Chief Examiner, Royal College of Psychiatrists

\section{Sexist language}

Sir: There is no dearth of sexist words that one comes across in daily life so there are a lot of sexist issues one can raise. People may even object to being referred to as 'him' or 'her' because it is discriminatory or against their gender identity. A news item (Oman Observer, 31 March 1994), mentions a Papua-New Guinea island where the language does not recognise gender differences and there are no terms like 'he' or 'she'. It has taken the lead from the civilised world. The problem may persist until a whole new non-sexist English evolves. After that, all sexist labels like Sir, Madam, Queen, King, ladies' club, stag party, women's lib, motherland etc., would become obsolete and replaced. Even a Mental state Examination, man-made, penis envy and patient management would become archaic!

I could not think of a really suitable alternative for 'Sir' to start this correspondence - and it seems that neither Dr Fiona Caldicott nor Dr Joanna MacDonald could think of it (Psychiatric Bulletin, March 1994, 18, 175). Could someone suggest a single non-sexist word that can be used to start such correspondence. The traditional 'Sir' may be inappropriate in more ways than one - the editor may neither be a man nor have a knighthood.

Maybe MENSA will come up with the equation, Mrs:Ms therefore Sir:Si? Until then, according to Dr Caldicott's quotation, let Sense and Sensibility reign.

Yousuf Kamal Mirza, Ibn Sina Hospital, PO Box 3, Al-Amerat, Muscat-119, Oman

Sir: The question raised by $\mathrm{Dr}$ Joanna MacDonald in the Psychiatric Bulletin, March 1994, 18, 175 is of considerable moment and many of us will be unable to sleep until it is resolved. The appearance of the word 'man' as the component of a longer word is a challenge, a provocation or, a cause of concern and disappointment to some people, and as members of a caring, indeed sharing, profession, we should not pass by on the other side.

Dr MacDonald suggests the word 'workforce', and we must be grateful for a possible way out of this semantic and political dilemma. However, I am troubled by the word 'force', with its connotations of power and militarism and hint of phallocentrism. Our own police have long dropped the epithet 'police force' in favour of 'police service', and we should be thankful for that. Further, the word workforce conveys an image of the labouring classes in serried ranks and this succeeds, unfortunately, in being collectivist and élitist at the same time. I think we should leave 'force' out of it.

I don't have a suggestion to make except to hope that the debate continues. However, I do want to express my profound admiration for our President's reply, which is a masterpiece of statesmanship and literary allusion in keeping with the motto of the College.

DEREK STEINBERG, Ticehurst House Hospital, Ticehurst, East Sussex TN5 7HU 